\title{
STUDIES ON THE INITIATION OF BLOOD COAGULATION. III. THE CLOTTING PROPERTIES OF CANINE PLATELET- FREE PLASMA ${ }^{1}$
}

\author{
BY ROBERT C. HARTMANN ${ }^{2}$ AND C. LOCKARD CONLEY WITH THE TECHNICAL \\ ASSISTANCE OF EDWIN L. POOLE
}

(From the Department of Medicine, The Johns Hopkins University and Hospital, Baltimore, $M d$.)

(Submitted for publication March 3, 1952; accepted April 16, 1952)

The changes which take place in shed blood and thereby initiate its coagulation remain a source of considerable speculation. It is still common belief that platelets are necessary for the initiation of blood coagulation although a number of investigators have presented evidence to the contrary $(1-8)$. While platelets appear to be essential for efficient clotting, there is good evidence that coagulation can occur in their absence. Investigations in this laboratory revealed that human platelet-free plasma, prepared without anticoagulant, regularly clotted in glass tubes at $37^{\circ} \mathrm{C}$ (7). However, aliquots of the same plasma clotted much more slowly or not at all in silicone-treated tubes. It was demonstrated that the rate of clotting of platelet-free plasma was directly related to the area of the glass surface to which the plasma was exposed. These studies were interpreted as providing evidence for the existence of a "plasma thromboplastin" which is activated on contact with glass surfaces and can bring about clotting in the absence of platelets $(7,8)$.

On the other hand Patton and his associates obtained different results with canine plasma using similar techniques (9). In their experiments canine plasma was freed of formed elements by high-speed centrifugation. This plasma when stored at room temperature was observed to clot imperfectly or not at all. Fibrin formation occurred with equal frequency in glass and siliconetreated tubes. These authors interpreted their results as providing no evidence for the view that plasma contains a soluble factor which can initiate clotting independent of platelet action.

\footnotetext{
1 This investigation was supported in part by a research grant from the Division of Research Grants and Fellowships of the National Institutes of Health, U. S. Public Health Service.

${ }^{2}$ Postdoctorate Fellow, U. S. Public Health Service.
}

The apparent differences in the clotting activity of human and canine platelet-free plasma might be attributable to a species variation. For this reason it seemed of interest to study the clotting properties of canine plasma with the techniques previously employed for human plasma. The results demonstrated that canine platelet-free plasma clotted when exposed to glass surfaces, and that the rate of clotting was related to the glass surface area. The clotting activity of canine plateletfree plasma was qualitatively similar to that of human plasma, but there were slight quantitative differences. These differences accounted for the apparent discrepancy between results previously obtained with dog and human plasma.

\section{METHODS AND MATERIALS}

Preparation of platelet-free plasma: Normal fasting dogs, weighing 7 to 21 kilograms, were anesthetized by the injection into a saphenous vein of sodium pentobarbital, $30 \mathrm{mg}$. per kilogram. Blood specimens were obtained by jugular venipuncture. Silicone ${ }^{3}$-treated needles, syringes, and tubes were employed. A multiple syringe technique was used in order to eliminate contamination with tissue juice. After about $10 \mathrm{ml}$. of blood had been withdrawn, the syringe was replaced by another which had been treated both with silicone and with silicone oil.4 Thirty to $50 \mathrm{ml}$. of blood were then withdrawn, carefully transferred to silicone-treated tubes, and centrifuged at 12,000 RPM for 10 minutes in a Sorvall angle centrifuge at $2^{\circ} \mathrm{C}$. The upper portion of the plasma was carefuly removed with a silicone-treated pipet and stored in silicone-treated tubes in an icebath. No anticoagulant was used. Plasma prepared in this manner in many instances contained no more than 10 platelets per cmm.

Clotting times: The clotting times of $1 \mathrm{ml}$. portions of blood or plasma were determined in scrupulously clean Pyrex test tubes $\left(13 \times 100 \mathrm{~mm}\right.$.) at $37^{\circ} \mathrm{C}$. In whole blood clotting time determinations three tubes were employed,

${ }^{3}$ Dri-Film 9987, General Electric Co.

4 Silicone Oil 9996-200 centistokes, General Electric Co. 
the clotting time being recorded as that found in the final tube. Clotting times on normal pound dogs varied between 17 and 36 minutes, values similar to those obtained with human blood. In clotting time determinations on platelet-free plasma two tubes were employed.

Prothrombin times: The one-stage method was employed. Rabbit brain thromboplastin was prepared according to the technique of Brambel (10). In normal dogs the prothrombin times varied from seven to $11 \mathrm{sec}-$ onds, depending on the particular lot of thromboplastin employed.

Platelet counts: Platelet counts on whole blood were performed by a routine method employing Rees-Ecker diluent. Platelet counts on centrifuged plasma were performed by a method previously described (7). In essence this consists of enumerating the total number of platelets in $0.9 \mathrm{cmm}$. of undiluted plasma in a Spencer "Bright-Line" counting chamber with a silicone-treated coverslip.

Fibrinogen determinations: The fibrinogen concentrations of plasma were determined by the method of Ratnoff and Menzie (11).

Preparation of crushed glass: The preparation of crushed glass particles has been described (8). Those particles which passed through a 50 mesh screen but were retained by a 100 mesh screen were used.

Preparation of barbital buffer: The buffer solution was composed of 7.3 grams sodium chloride, 2.76 grams barbital, 2.06 grams sodium barbital, and sufficient distilled water to bring the total volume to one liter. The mixture was heated gently without boiling to facilitate solution. The $\mathrm{pH}$ of this isotonic material was $7.5 \pm 0.1$.

\section{RESULTS}

High speed centrifugation of canine blood in silicone-treated tubes at low temperatures regularly resulted in the virtual elimination of platelets from the supernatant plasma. Direct microscopic examination of this undiluted native plasma revealed fewer than 70 platelets per $\mathrm{cmm}$., and in many instances no more than five platelets per $\mathrm{cmm}$. were observed. The plasma was clear and showed no evidence of clot formation when stored in siliconetreated tubes at $2^{\circ} \mathrm{C}$ for a period of observation of 24 hours.

A number of observations suggest that the clotting components of this native plasma were unaltered by centrifugation except for the removal of formed elements. The addition of rabbit brain thromboplastin to platelet-free plasma in siliconetreated tubes at $37^{\circ} \mathrm{C}$ brought about complete clot formation in less than 12 seconds. Furthermore, the prothrombin time of the platelet-free plasma was the same as that of plasma obtained from oxalated blood by low-speed centrifugation. No appreciable change in the fibrinogen concentration of the plasma occurred during the centrifugation process. In most of the experiments platelet-free plasma did not clot when stored for 24 hours in silicone-treated tubes at $37^{\circ} \mathrm{C}$. When platelet-free plasma was oxalated no evidence of clot formation was observed during 24 hours storage at $37^{\circ} \mathrm{C}$ even in the presence of an excess of crushed glass. These observations indicate that thrombin was not formed during the preparation of the plasma.

Platelet-free plasma was prepared in 22 experiments from the blood of 15 dogs. One experiment will be described in detail:

A fasting mongrel dog weighing 13.6 kilograms was anesthetized by the intravenous injection of $410 \mathrm{mg}$. sodium pentobarbital into a saphenous vein. Blood was drawn from a jugular vein using the technique described in the section on methods and materials. The clotting time of the whole blood in three tubes was 16,16 , and 22 minutes. A portion of the blood was oxalated by the addition of $10 \%$ by volume of $\mathrm{M} / 10$ sodium oxalate solution, and centrifuged at low speed for approximately 10 minutes. The prothrombin time of the supernatant plasma on repeated determinations was seven, eight, seven, and eight seconds. Another portion of the dog's blood was oxalated by introducing $5 \mathrm{ml}$. of the blood into a tube containing $4 \mathrm{mg}$. of potassium oxalate and $6 \mathrm{mg}$. ammonium oxalate. This oxalated blood was also centrifuged at low speed and the supernatant plasma was found to contain fibrinogen in a concentration of 299 and $307 \mathrm{mg}$. per $100 \mathrm{ml}$. plasma in duplicate determinations.

Forty ml. of the dog's blood were placed in tubes which were coated both with silicone and silicone oil. These tubes, which were immersed in an icebath, were transferred to the refrigerated centrifuge. They were then centrifuged at 12,000 RPM for 10 minutes. The upper portion of the supernatant plasma was carefully removed with a silicone-treated pipet.

Direct microscopic observation of this undiluted plasma in a counting chamber revealed that there were six platelets per $\mathrm{cmm}$. A portion of the plasma was oxalated by the addition of one part of $\mathrm{M} / 10$ sodium oxalate solution to five parts of native plasma. The prothrombin time was seven seconds on four determinations. Another portion of plasma was added to a tube containing dry ammonium and potassium oxalate in the proportions noted above. The fibrinogen concentration of this plasma was 291 and $287 \mathrm{mg}$. per $100 \mathrm{ml}$. on duplicate determinations.

One ml. portions of plasma were placed into pairs of Pyrex test tubes which had been prepared as follows: one pair was treated with silicone and the remaining three pairs were not treated with silicone, but in one pair 
$150 \mathrm{mg}$. of crushed glass were added and in another pair $800 \mathrm{mg}$. The tubes were kept in a waterbath at $37^{\circ} \mathrm{C}$ and observed for evidences of clotting. After 24 hours the plasma kept in silicone-treated tubes was perfectly clear and showed no evidence of coagulation. Partial clots were observed in the plain glass tubes at the end of 24 hours. The plasma in the tubes containing $150 \mathrm{mg}$. of crushed glass was solidly clotted in 10 hours, and that in tubes containing $800 \mathrm{mg}$. of crushed glass was solidly clotted in less than six hours.

At the end of 24 hours the clear plasma in the siliconetreated tubes was transferred to glass tubes containing $800 \mathrm{mg}$. of crushed glass. No clots were observed during a further incubation period of 24 hours at $37^{\circ} \mathrm{C}$. However, the addition of a preparation of rabbit brain thromboplastin caused coagulation to occur in 10 seconds, exactly the same interval required for coagulation of this plasma prior to incubation. On the other hand a portion of this plasma which had been stored at $2^{\circ} \mathrm{C}$ for 24 hours clotted when exposed to crushed glass at $37^{\circ} \mathrm{C}$.

In this experiment virtually platelet-free canine plasma did not clot in silicone-treated tubes after prolonged storage at $37^{\circ} \mathrm{C}$, but coagulation did occur in glass tubes. The rate of clotting was directly related to the glass surface area to which the plasma was exposed.

TABLE I

Clotting activity of canine platelet-free plasma

\begin{tabular}{|c|c|c|c|c|c|c|}
\hline \multirow{4}{*}{$\begin{array}{l}\text { Experi- } \\
\text { ment } \\
\text { No. }\end{array}$} & \multirow{4}{*}{$\begin{array}{l}\text { Whole } \\
\text { blood } \\
\text { clotting } \\
\text { time in } \\
\text { glass } \\
\text { tubes at } \\
37^{\circ} \mathrm{C}\end{array}$} & \multicolumn{5}{|c|}{ Native platelet-free plasma } \\
\hline & & \multirow{3}{*}{ Platelets } & \multicolumn{4}{|c|}{ Clotting time of $1 \mathrm{ml}$. portions at $37^{\circ} \mathrm{C}$} \\
\hline & & & \multirow{2}{*}{$\begin{array}{l}\text { Silicone } \\
\text { tube }\end{array}$} & \multicolumn{3}{|c|}{$\begin{array}{l}\text { Glass tubes with added } \\
\text { crushed glass }\end{array}$} \\
\hline & & & & $\mathbf{0}$ & $150 \mathrm{mg}$. & $800 \mathrm{mg}$. \\
\hline $\begin{array}{r}1 \\
2 \\
3 \\
4 \\
5 \\
6 \\
7 \\
8 \\
9 \\
10 \\
11 \\
12 \\
13 \\
14 \\
15 \\
16 \\
17 \\
18 \\
19 \\
20 \\
21\end{array}$ & $\begin{array}{c}\min . \\
18 \\
24 \\
24 \\
22 \\
24 \\
27 \\
28 \\
23 \\
32 \\
17 \\
22 \\
23 \\
20 \\
17 \\
24 \\
36 \\
23 \\
25 \\
24 \\
19 \\
22\end{array}$ & $\begin{array}{c}\text { per } \mathrm{cmm} \text {. } \\
-3 \\
5 \\
3 \\
1 \\
7 \\
57 \\
68 \\
32 \\
5 \\
10 \\
- \\
4 \\
5 \\
5 \\
- \\
66 \\
8 \\
33\end{array}$ & $\begin{array}{c}\text { min. } \\
\infty * \\
\infty \\
\infty \\
\infty \\
\infty \\
\infty \\
\infty \\
\infty \\
\infty \\
\infty \\
\infty \\
\text { P.C.† } \\
\text { P.C. } \\
\text { P.C. } \\
\text { P.C. } \\
\text { P.C. } \\
<22 \text { hrs. } \neq \\
\infty \\
<22 \text { hrs. } \\
\infty \\
\infty\end{array}$ & $\begin{array}{c}\text { min. } \\
\infty \\
\infty \\
\infty \\
\infty \\
\infty \\
\infty \\
\infty \\
\infty \\
\infty \\
\infty \\
\infty \\
\text { P.C. } \\
\text { P.C. } \\
\text { P.C. } \\
\text { P.C. } \\
\text { P.C. } \\
<22 \text { hrs. } \\
\text { P.C. } \\
\text { P.C. } \\
\text { P.C. } \\
40\end{array}$ & $\begin{array}{c}\text { min. } \\
61 \\
\text { P.C. } \\
13 \\
<22 \text { hrs. } \\
\text { P.C. } \\
12 \\
<22 \text { hrs. } \\
<22 \text { hrs. } \\
\text { P.C. } \\
\infty \\
12 \\
14 \\
5 \\
<22 \text { hrs. } \\
7 \\
<22 \text { hrs. } \\
<22 \text { hrs. } \\
14 \\
18 \\
42 \\
10\end{array}$ & $\begin{array}{c}\min . \\
12 \\
36 \\
10 \\
11 \\
\text { P.C. } \\
11 \\
20 \\
<22 \mathrm{hrs} . \\
51 \\
33 \\
12 \\
9 \\
4 \\
<22 \mathrm{hrs} . \\
5 \\
<22 \mathrm{hrs} . \\
18 \\
11 \\
11 \\
27 \\
7\end{array}$ \\
\hline
\end{tabular}

$*_{\infty}=$ No clot at end of 24 hours.

+ P.C. = Partial clot at end of 24 hours.

$\ddagger<22$ hrs. = Complete clotting occurred at some time between six and 22 hours, but the exact time was not detérmined.
TABLE II

Clotting activity of canine platelet-free plasma: effect of dilution of plasma with barbital buffer solution

\begin{tabular}{c|c|c|c|c}
\hline & \multicolumn{3}{|c}{ Clotting time of $1 \mathrm{ml}$. portions at $37^{\circ} \mathrm{C}$} \\
\cline { 2 - 4 } $\begin{array}{c}\text { Concentration } \\
\text { of plasma }\end{array}$ & $\begin{array}{c}\text { Silicone } \\
\text { tube }\end{array}$ & \multicolumn{2}{|c}{ Glass tubes with added crushed glass } \\
\cline { 2 - 4 } & min. & min. & min. & min. \\
100 & $\infty *$ & $\infty$ & $<22$ hrs.f & 20 \\
80 & $\infty$ & P.C. $\begin{array}{c}20 \\
14\end{array}$ & 14 \\
50 & 38 & 26 & 14 & 11 \\
20 & 36 & 27 & 20 & 14 \\
\hline
\end{tabular}

$* \infty=$ No clot at end of 24 hours.

$\dagger$ P.C. = Partial clot at end of 24 hours.

$\ddagger<22$ hrs. = Complete clotting occurred at some time between six and 22 hours, but the exact time was not determined.

Data of 21 similar experiments are summarized in Table I. In the majority of the experiments there was no difference in the rate and degree of clotting in silicone-treated and in plain glass tubes without added crushed glass. In 11 experiments no clotting occurred in either silicone-treated or plain glass tubes. In six experiments markedly delayed or incomplete clotting, often consisting of only a few fibrin strands, occurred but the rate and degree of clotting were the same in both glass and silicone-treated tubes. These findings are in essential agreement with those of Patton and his associates (9), and in so far as they go might suggest that surface plays no role in the clotting of platelet-free plasma. However, in every instance increasing the glass surface area by the addition of crushed glass caused clotting to occur. The rapidity of clotting was directly related to the amount of crushed glass. In the foregoing experiments there was no relationship between the clotting behavior of the plasma and the precise number of platelets remaining.

When the platelet-free plasma was quickly frozen and then thawed, its clotting activity was not appreciably altered. Such plasma, if not permitted to come in contact with glass at any time, remained fluid when kept for 24 hours at $37^{\circ} \mathrm{C}$. However, thawed plasma was readily clotted by the addition of crushed glass. Similarly the clotting properties of platelet-free plasma were retained after storage at $2{ }^{\circ} \mathrm{C}$ for 24 hours. However, when plasma was stored at $37^{\circ} \mathrm{C}$ for 24 hours, it could not subsequently be clotted by the 


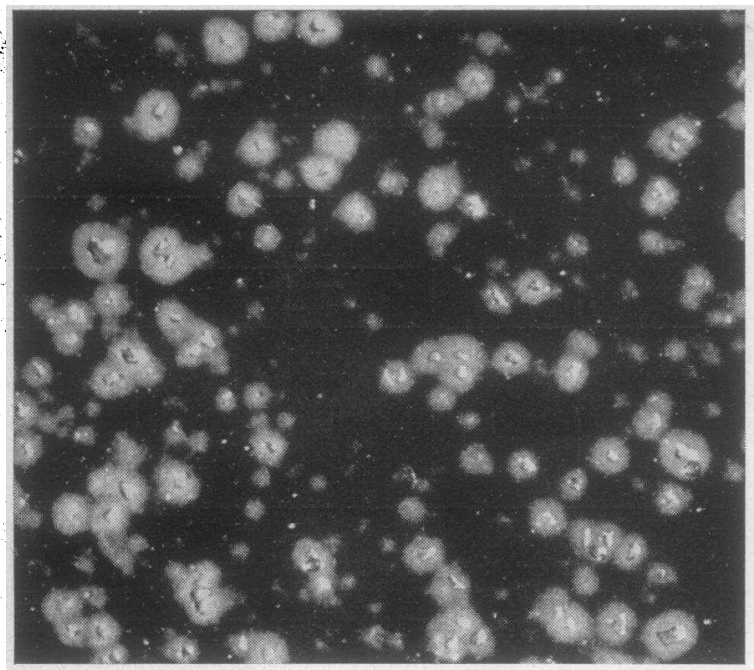

Fig. 1. The Appearance of Canine Platelet-Free Plasma Clotting in Contact with Crushed Glass

The clots formed about the glass particles, and in the areas between the particles coagulation is not evident. (Enlarged $\times 6$.)

addition of large amounts of crushed glass. A1though this stored plasma did not react to the clot-accelerating effect of glass surfaces, it was promptly clotted by the addition of tissue extract thromboplastin.

The effect of dilution of platelet-free plasma with barbital buffer solution was studied. It can be seen from the data shown in Table II that dilution of plasma accelerated the degree and speed of clotting. Plasma which did not clot in siliconetreated and plain glass tubes clotted following dilution with buffer, thus providing additional evidence that canine platelet-free plasma contained all of the components necessary for coagulation. The rate of clotting of diluted plasma was a function of the glass surface area. The barbital buffer solution was prepared in such a manner as to prevent contamination with thromboplastic substances. Furthermore, the addition of this buffer solution to hemophilic platelet-free plasma did not cause clotting to occur. ${ }^{5}$ There is thus no evidence that the clot-accelerating effect of dilution with buffer solution was due to inherent thromboplastic properties of the latter.

\footnotetext{
5 Hemophilic platelet-free plasma provides a sensitive means for detecting the presence of thromboplastin. Such plasma does not clot spontaneously but is clotted by extraordinarily minute amounts of thromboplastin.
}

Similar results were obtained when $0.85 \%$ sodium chloride solution was used as the diluent.

\section{Direct visual observation of the clotting of canine. platelet-free plasma}

Clotting of platelet-free plasma was observed using a phase contrast microscope. Glass slides and coverslips were coated with silicone. A few particles of crushed glass were placed on the surface of the glass slide. Platelet-free plasma was introduced between the slide and coverslip and the preparation sealed with vaseline.

In preparations of this type platelets are easily recognized when present. However, in the numerous specimens examined, no platelets were seen. After about 15 minutes a fine fibrin network could be seen at the surface of the glass particles. As clot formation progressed a fibrin collar was formed around each piece of glass. Subsequently this structure became macroscopically visible with a rounded area of clot surrounding each glass particle. In regions remote from the glass the appearance of fibrin was much delayed. Figure 1 shows the appearance of such a preparation.

\section{The clotting activity of platelet-free plasma ob- tained from a hemophilic dog}

Graham and his associates have described the characteristics of a hemorrhagic disease occurring in Irish setters (12). The hereditary pattern, clinical picture, and laboratory data in these animals were identical with those seen in human hemophilia. Opportunity was afforded to study an apparently identical situation in several members of a litter of pure-bred English setters.

The bitch, a vigorous and healthy animal, had had three litters. Some of the males in the first litter were known to have died following the development of multiple hematomas. The second litter consisted of four females and two males, none of which displayed manifestations of a hemorrhagic diathesis. The third litter contained four healthy pups two of which were males. However, three other males showed striking evidence of a hemorrhagic disorder. All developed enormous and apparently painful hematomas, particularly over the back and scalp, and evidence of dysfunction of the hip joints. These manifestations became apparent between the third and sixth weeks of life. Because of their painful disability it was necessary to sacrifice these dogs when they were about three months of age. 
TABLE III

Studies on canine hemophilia in two litter mates

\begin{tabular}{|c|c|c|}
\hline . & Dog No. 1 & Dog No. 2 \\
\hline $\begin{array}{l}\text { Whole blood clotting time (min.) } \\
\text { Prothrombin time (sec.) } \\
\text { "Prothrombin consumption"* }\end{array}$ & $\begin{array}{r}320 \\
9 \\
\text { Markedly }\end{array}$ & $\begin{array}{r}>360 \\
9 \\
\text { Markedly }\end{array}$ \\
\hline $\begin{array}{l}\text { Platelets (per cmm.) } \\
\text { Fibrinogen (mg. per } 100 \mathrm{ml} . \text { ) } \\
\text { Clot retraction } \\
\text { Test for circulating anticoagulant (14) }\end{array}$ & $\begin{array}{r}192,000 \\
360 \\
\text { Normal } \\
\end{array}$ & $\begin{array}{r}230,000 \\
300 \\
\text { Normal } \\
\text { Negative }\end{array}$ \\
\hline
\end{tabular}
(13).

* Modification of the method of Quick and Favre-Gilly

Two of the three animals were available for study, and the results are shown in Table III. These are identical with those seen in human hemophilia, with normal prothrombin, platelet, and fibrinogen concentrations, and negative test for circulating anticoagulant, as well as markedly prolonged whole blood clotting time and impaired "prothrombin consumption."

Platelet-free plasma was prepared from the blood of Dog. No. 2. This plasma failed to clot in silicone-treated or glass tubes. The addition of as much as $800 \mathrm{mg}$. of crushed glass to $1 \mathrm{ml}$. of plasma did not cause coagulation to occur. However, the addition of tissue extract thromboplastin brought about rapid clotting. When rabbit brain suspension was added to the platelet-free plasma, coagulation occurred in 10 seconds in duplicate determinations.

\section{DISCUSSION}

In these experiments a relatively stable native platelet-free plasma was readily produced from canine blood. In most instances this native plasma failed to clot in silicone-treated tubes even after prolonged incubation at $37^{\circ} \mathrm{C}$. Furthermore, canine plasma usually showed no evidence of coagulation when stored in plain glass tubes. However, when the area of glass surface was increased by the addition of crushed glass, clotting invariably occurred, the rate being related to the amount of glass present. When plasma was diluted with buffer solution, coagulation occurred even in silicone-treated tubes. Furthermore, the coagulation of diluted plasma was accelerated by exposure to glass surfaces. These observations demonstrated that those substances necessary for the initiation of coagulation were all present in platelet-free plasma. Careful studies indicated that in the preparation of this plasma no significant changes occurred other than the removal of the formed elements of the blood. Direct microscopic observation provided impressive confirmation of the manner in which glass surfaces initiated coagulation in platelet-free plasma.

In contrast to the behavior of normal canine plasma, hemophilic dog plasma failed to clot on exposure to glass surfaces, although it was as readily clotted by tissue thromboplastin as was normal plasma. This suggests that hemophilic plasma may be deficient in a substance upon which glass surfaces exert their effect.

The observations on dog plasma, while similar to those made on human plasma, showed a significant difference. Canine platelet-free plasma was somewhat more stable than human plasma. It was possible to produce platelet-free plasma which did not clot in silicone-treated tubes more regularly than in experiments on human plasma $(7,8)$. Furthermore, the amount of glass surface required to bring about coagulation of dog plasma exceeded that necessary for human plasma.

These studies were interpreted as presenting evidence for the existence of a soluble factor in canine as well as human plasma which can initiate clotting independent of platelet action. This factor which has been called "plasma thromboplastin" appears to exist in circulating blood in an inactive form which can be activated on contact with glass surfaces $(7,8)$. In both species the substance which was activated on contact with glass surfaces appeared to be relatively stable at $2^{\circ} \mathrm{C}$ but lost activity within 24 hours at $37^{\circ} \mathrm{C}$.

Platelet-free plasma from hemophilic human subjects clotted not at all or only after great delay on contact with glass surfaces. In many instances the addition of as much as $800 \mathrm{mg}$. of crushed glass to $1 \mathrm{ml}$. of platelet-free plasma failed to produce any evidence of clotting (15). In canine hemophilia identical results were obtained. These findings suggest that there is a deficiency of plasma thromboplastin in hemophilia in both species. Plasma thromboplastin may be identical with the antihemophilic globulin of Patek and Stetson (16).

The manner in which glass surfaces activate plasma thromboplastin is unknown. It is possible 
that the plasma factor is normally bound to an inhibitor. Such an inhibitor might be adsorbed on glass and other similar surfaces. The acceleration of clotting brought about by the dilution of plasma could be explained by the dilution of an inhibitor. This is a point which has been repeatedly emphasized by Tocantins and others, who have attributed the clotting defect in hemophilia to an excess of such an inhibitor (17-19). We have been unable to demonstrate an excess of an inhibitor in the blood of patients with hemophilia $(14,20)$. In our experience the dilution of hemophilic platelet-free plasma has not caused coagulation to occur, even in the presence of an excess of crushed glass, in those instances in which the undiluted plasma failed to clot $(15,20)$. If such an inhibitor does exist, it does not appear to be of the type which can be demonstrated to have an anticoagulant effect on normal blood. However, it is conceivable that an inhibitor is bound to activator and that there is no excess present (18).

While it remains to be proved that a thromboplastin inhibitor is normally present in blood, a specific and easily demonstrable inhibitor of plasma thromboplastin has been found in the blood of certain patients with a hemorrhagic disorder. This substance, which acts as a potent anticoagulant, appears to inhibit only the activation of plasma thromboplastin and has no effect on other stages of blood coagulation. A study of the properties of this anticoagulant has provided further support for the existence of a plasma thromboplastin (21).

The question is often raised whether the effect of glass surfaces on centrifuged plasma might be mediated by the few remaining platelets. In the present experiments the plasmas appeared to be virtually free of platelets. In a previous study on human plasma it was shown that the small number of platelets remaining after centrifugation were probably not concerned with the clotaccelerating effect of glass (8). Furthermore, a globulin fraction prepared from human plateletfree plasma did not clot when protected from contact with glass, but clotted readily when exposed to glass surfaces (22). In this globulin fraction it seems likely that intact platelets were not present.
Although the plasma factor is able to initiate coagulation in the absence of platelets, there is no question that the platelets accelerate the conversion of prothrombin to thrombin. For normal clotting both the platelets and plasma factor are required. The relationship between the platelets and plasma factor is not understood. The present studies provide no support for the theory that a platelet enzyme is necessary for the activation of the plasma thromboplastin (23). Neither are these studies compatible with the concept that the plasma factor produces thromboplastin only by exerting a lytic effect on platelets (24). There is no question that platelets, like other cellular structures, contain a small amount of thromboplastin which may eventually be released in shed blood. Thus, hemophilic plasma, presumably deficient in plasma thromboplastin, will not clot in the absence of platelets, but hemophilic plasma containing a normal complement of platelets will eventually clot. It appears that either the plasma thromboplastin or platelets alone can initiate coagulation, but for efficient clotting both components are required (7). The reported studies suggest that the clot-accelerating effect of glass surfaces is mediated by the plasma factor rather than by any direct action on platelets. It seems likely that the platelets accelerate the conversion of prothrombin to thrombin after the activation of the plasma thromboplastin has occurred.

\section{SUMMARY}

1. Platelet-free plasma was prepared from the blood of dogs without the use of anticoagulants by means of high-speed centrifugation at low temperature using silicone-treated apparatus.

2. Platelet-free plasma obtained from normal dogs usually remained fluid when stored at $37^{\circ} \mathrm{C}$ in silicone-treated tubes but clotted on contact with crushed glass. The rate of clotting was directly related to the glass surface area.

3. Hemophilic dog plasma from which the platelets had been removed did not clot even when stored in contact with crushed glass.

4. These observations support the view that the clot-accelerating effect of glass surfaces is mediated by a "plasma thromboplastin." This factor is apparently deficient in hemophilia. 


\section{REFERENCES}

1. Bordet, J., and Gengou, O., Recherches sur la coagulation du sang et les sérums anticoagulants. Ann. Inst. Pasteur, 1901, 15, 129.

2. Gratia, A., L'action du contact sur la coagulation du sang. J. de physiol. et de path. gén., 1916-18, 17, 722.

3. Nolf, P., The coagulation of the blood. Medicine, 1938, 17, 381.

4. Lenggenhager, $\mathrm{K}$., Irrwege der Blutgerinnungsforschung. Klin. Wchnschr., 1936, 15, 1835.

5. Feissly, R., Séparation des facteurs plasmatiques intervenant dans la formation de la thrombine. Helvet. med. Acta, 1941, 7, 583.

6. Lozner, E. L., and Taylor, F. H. L., The effect of foreign surfaces on blood coagulation. J. Clin. Invest., 1942, 21, 241.

7. Conley, C. L., Hartmann, R. C., and Morse, W. I., II, The clotting behavior of human "platelet-free" plasma: evidence for the existence of a "plasma thromboplastin." J. Clin. Invest., 1949, 28, 340.

8. Hartmann, R. C., Conley, C. L., and Lalley, J. S., Studies on the initiation of blood coagulation. I. The relationship of platelets to the clot-promoting effect of glass surfaces. Bull. Johns Hopkins Hosp., 1949, 85, 231.

9. Patton, T. B., Ware, A. G., and Seegers, W. H., Clotting of plasma and silicone surfaces. Blood, 1948, 3, 656.

10. Brambel, C. E., Thromboplastic reagent. Arch. Surg., 1945, 50, 137.

11. Ratnoff, O. D., and Menzie, C., A new method for the determination of fibrinogen in small samples of plasma. J. Lab. \& Clin. Med., 1951, 37, 316.

12. Graham, J. B., Buckwalter, J. A., Hartley, L. J., and Brinkhous, K. M., Canine hemophilia. Observations on the course, the clotting anomaly, and the effect of blood transfusions. J. Exper. Med., 1949, 90, 97.

13. Quick, A. J., and Favre-Gilly, J. E., The prothrombin consumption test; its clinical and theoretic implications. Blood, 1949, 4, 1281.
14. Conley, C. L., Hartmann, R. C., and Morse, W. I., II, Circulating anticoagulants: a technique for their detection and clinical studies. Bull. Johns Hopkins Hosp., 1949, 84, 255.

15. Hartmann, R. C., and Conley, C. L., Unpublished observations.

16. Patek, A. J., Jr., and Stetson, R. P., Hemophilia; the abnormal coagulation of the blood, and its relation to blood platelets. J. Clin. Invest., 1936, 15, 531.

17. Tocantins, L. M., Relation of contacting surface and anticephalin activity to the maintenance of the fluidity and coagulability of blood. Blood, 1946, 1, 156.

18. Tocantins, L. M., Carroll, R. T., and Holburn, R. H., The clot accelerating effect of dilution on blood and plasma. Relation to the mechanism of coagulation of normal and hemophilic blood. Blood, 1951, 6, 720.

19. Feissly, R., Nouvelles études sur l'hémophilie. IV. Propriétés du plasma traité par le kaolin. Helvet. med. Acta, 1946, 13, 313.

20. Hartmann, R. C., Conley, C. L., and Lalley, J. S., The nature of the coagulation defect in hemophilia: studies on platelet-free plasmas. Am. J. Med., 1949, 6, 507.

21. Conley, C. L., Ratnoff, O. D., Ellicott, C. E., and Hartmann, R. C., Studies on the initiation of blood coagulation. II. An anticoagulant inhibiting the activation of a plasma thromboplastic factor. J. Clin. Invest., 1950, 29, 1182.

22. Ratnoff, O. D., and Conley, C. L., The rôle of surface and of calcium in the coagulation of a globulin fraction of platelet-deficient plasma. Bull. Johns Hopkins Hosp., 1951, 89, 245.

23. Quick, A. J., Quantitative studies on the coagulation defect in hemophilia. Federation Proc., 1947, 6, 284.

24. Brinkhous, K. M., Clotting defect in hemophilia : deficiency in a plasma factor required for platelet utilization. Proc. Soc. Exper. Biol. \& Med., 1947, 66, 117. 